\title{
Characterization and Modeling of Room-Temperature Compressive Creep Behavior of a Near $\alpha$ TA31 Titanium Alloy
}

\author{
Weixin Yu ${ }^{1, *(\mathbb{D})}$, Shusen Hou ${ }^{1}$, Zhijun Yang ${ }^{1}$, Jinyong Zhang ${ }^{2,3, *}$ and Shaoting Lang ${ }^{1} \mathbb{C}$ \\ 1 School of Mechanical and Electrical Engineering, Xinxiang University, Xinxiang 453003, China; \\ shusen_hou@163.com (S.H.); yzj165@163.com (Z.Y.); shaotinglang@163.com (S.L.) \\ 2 School of Material Science and Engineering, China University of Mining and Technology, \\ Xuzhou 221008, China \\ 3 State Key Laboratory of Solidification Processing, Northwestern Polytechnical University, \\ Xi'an 710072, China \\ * Correspondence: yuweixin2012@163.com (W.Y.); jyzhang@cumt.edu.cn (J.Z.); \\ Tel.: +86-373-3682637 (W.Y.); +86-516-83591879 (J.Z.)
}

Received: 2 August 2020; Accepted: 29 August 2020; Published: 4 September 2020

\begin{abstract}
The creep behavior of a near $\alpha$ TA31 titanium alloy under different compressive pressures has been studied by long-time (up to $500 \mathrm{~h}$ ) compression tests at room temperature. The experimental results show that several thresholds of the compressive pressure were found to exist in the compression process of the TA31 alloy. When the compressive stress is lower than $0.80 \mathrm{Rp} 0.2$, there is no creep. There is a steady-state creep stage at the compressive stresses between $0.85 \mathrm{Rp} 0.2$ and $0.93 \mathrm{Rp} 0.2$, in which the strain rate is approximately a constant value. When the compressive stress reaches a threshold stress between $0.93 \mathrm{Rp} 0.2$ and $0.95 \mathrm{Rp} 0.2$, the sample enters the accelerating creep stage directly. The creep model of TA31 alloy has been built by using the regression method, from which the creep strain rate of TA31 titanium alloy in the steady-state creep stage under different compressive stress levels can be calculated. The mean difference between the calculated and the experimental value is $2.54 \%$, indicating the creep model can efficiently predict the creep behavior of TA31 alloy.
\end{abstract}

Keywords: TA31 titanium alloy; compression tests; compressive creep behavior; creep model

\section{Introduction}

The pressure-resistant structure is the most important carrier and safeguard for deep-sea equipment, such as submarines and submersibles, which determines the diving depth of the equipment. With the increase of submersible depth, it has become more and more difficult to meet the requirements of deep-sea equipment with the traditional steel pressure-resistant structure, while titanium alloy has obvious advantages in replacing traditional materials in deep-sea pressure-resistant structure due to its advantages of high specific strength, corrosion resistance, and low magnetism [1-4]. As a kind of near $\alpha$ titanium alloy for ship, TA31 titanium alloy also has good plastic toughness and weldability, which has a broad prospect in the field of marine and ocean engineering.

However, metal materials are prone to creep under high pressure in deep sea. Tanaket et al. [5] found that $\mathrm{CP}-\mathrm{Ti}$ and commercial Ti-6Al-4V titanium alloy still undergoes obvious creep deformation when the stress level is lower than the yield stress at room temperature. Ankem et al. [6] and Oberson et al. [7] analyzed the creep mechanism of titanium alloy at room temperature, in which it has been shown that twinning can be a very slow process and contribute to low-temperature creep deformation. Because the creep is usually a very slow process [8,9], the creep problem generally does not need to be considered when the submersible will be in the deep sea for a short time. However, 
the creep can have implications in the stability and reliability of stressed components when working in the deep sea for a long time. A large number of studies have been carried out on the tensile creep characteristics of titanium alloy at high temperature environment of aerospace fields [10-15], but there is rare study on compressive creep of marine titanium alloys. Therefore, in this paper, we study in detailed the creep behavior of a near $\alpha$ TA31 titanium alloy under different pressure levels has been studied by long-time (up to $500 \mathrm{~h}$ ) compression tests at room temperature. The creep model of the TA31 alloy has been built by using the regression method. The reliability of the model has been evaluated and verified.

\section{Materials and Methods}

The TA31 alloy used in this work was taken from a bar with a diameter of $25 \mathrm{~mm}$, which was produced by hot-forging in the $\alpha+\beta$ temperature range and then followed with a stress relief annealing treatment. The chemical composition of the TA31 alloy plate is given in Table 1, and the optical microstructure in the as-received condition is shown in Figure 1, which consisted of equiaxed primary alpha phase in a transformed beta matrix. The transit temperature $(\mathrm{T} \beta)$ of this alloy was determined as about $1000{ }^{\circ} \mathrm{C}$. The yield strength Rp0.2 of this alloy at room temperature was $765 \mathrm{MPa}$.

Table 1. Chemical composition of the TA31 titanium alloy (mass fraction, \%).

\begin{tabular}{cccccccc}
\hline $\mathbf{A l}$ & $\mathbf{Z r}$ & $\mathbf{M o}$ & $\mathbf{N b}$ & $\mathbf{C}$ & $\mathbf{N}$ & $\mathbf{H}$ & $\mathbf{O}$ \\
\hline 6.13 & 2.06 & 0.97 & 2.96 & 0.010 & 0.005 & 0.001 & 0.09 \\
\hline
\end{tabular}

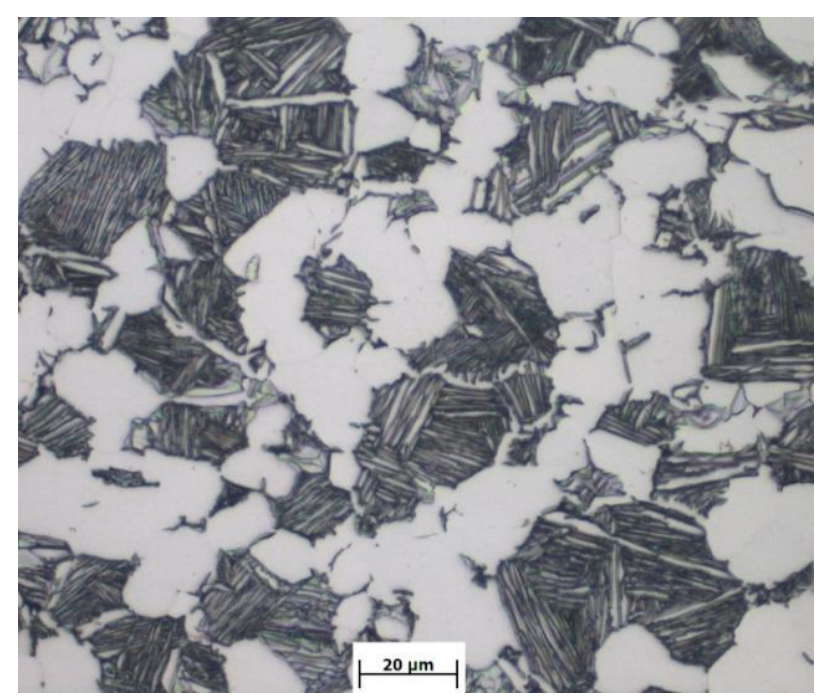

Figure 1. Optical microstructure of the TA31 titanium alloy in the as-received condition.

The compression-creep testing was performed at room temperature $\left(20^{\circ} \mathrm{C}\right)$ using an electro-hydraulic servo universal testing machine MTS-370-250KN (MTS, Eden Prairie, MN, USA) as shown in Figure $2 a$. The geometry of the compression creep specimen is shown in Figure 3, with a gauge section of $10 \mathrm{~mm}$ in diameter. The total length of the $10 \mathrm{~mm}$ diameter cylinder in the specimen is $30 \mathrm{~mm}$ as shown in Figure 3, and the gauge length used in the present study is $20 \mathrm{~mm}$. The extensometer MTS634.11E-24 (MTS, Eden Prairie, MN, USA) was attached to the gauge of the specimen (20 mm length) and compression displacement of the gauge was accurately recorded, as shown in Figure $2 \mathrm{~b}$. The compression displacement of the specimen was accurately recorded using the extensometer and transferred to the logger system which displays the corresponding compression strain under the applied stress and time. The compressive-creep tests were carried out at temperature of $20^{\circ} \mathrm{C}$ under selected stresses of 0.60Rp0.2, 0.70Rp0.2, 0.80Rp0.2, 0.85Rp0.2, 0.88Rp0.2, 0.90Rp0.2, 0.93Rp0.2, and $0.95 \mathrm{Rp} 0.2$ to holding times of $500 \mathrm{~h}$ and $200 \mathrm{~h}$, as shown in Table 2. 


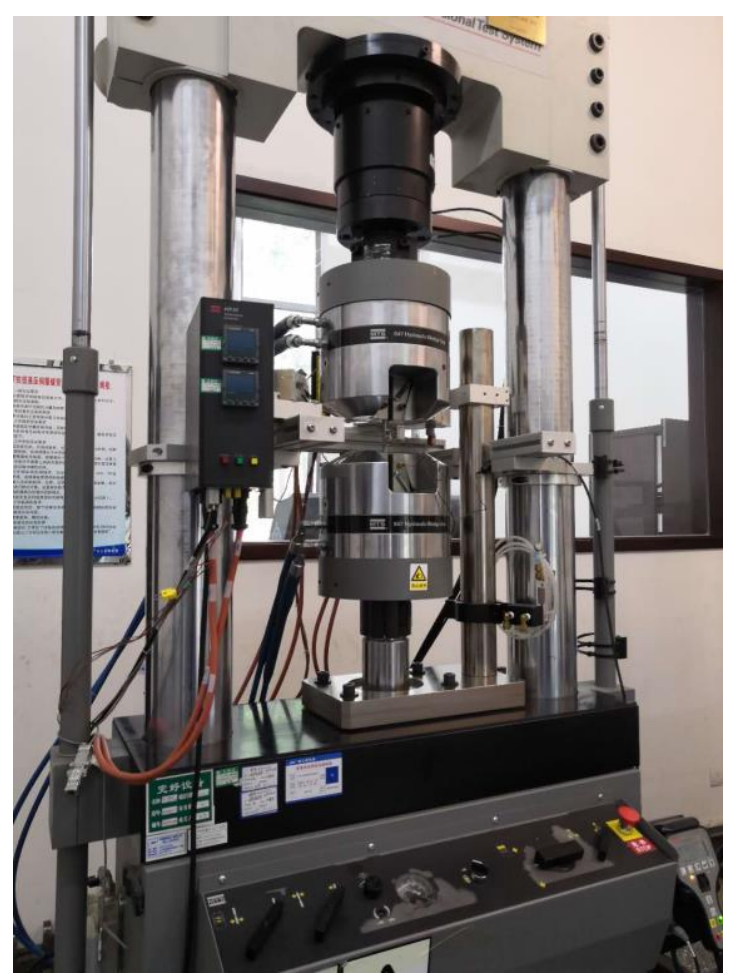

(a)

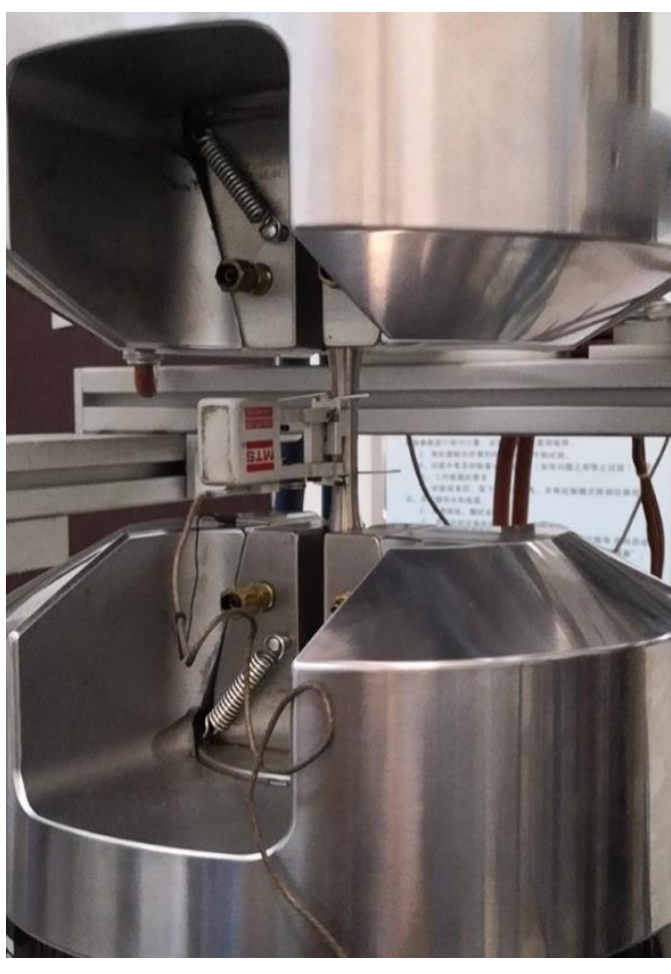

(b)

Figure 2. (a) Electro-hydraulic servo universal testing machine MTS-370-250KN; (b) specimen in the machine.

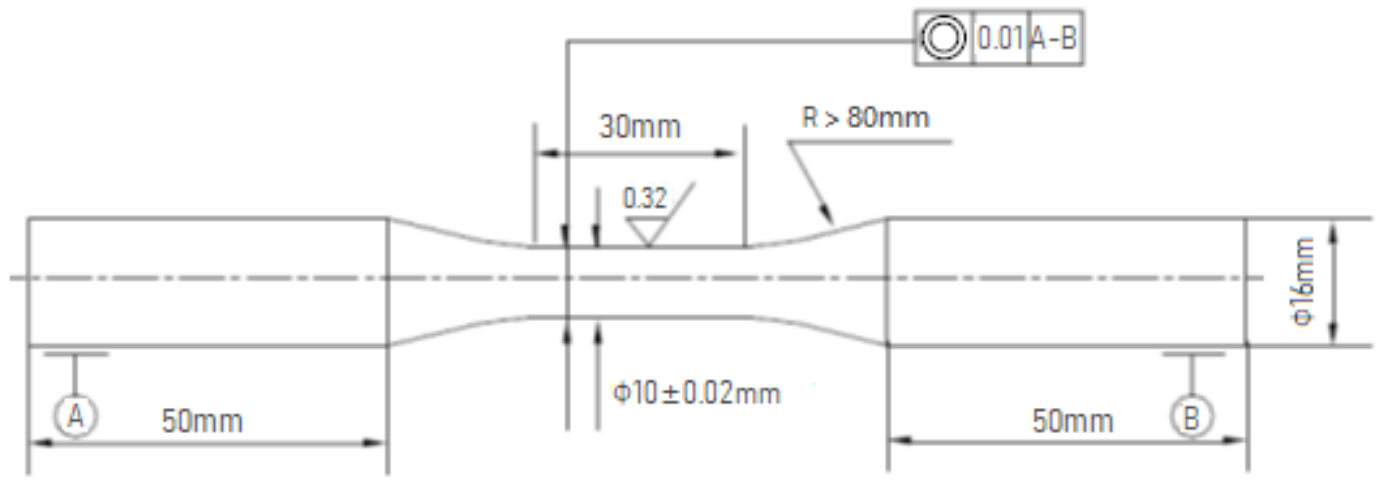

Figure 3. Compression creep specimen.

Table 2. Processing parameters used in the present study.

\begin{tabular}{cccc}
\hline Test No. & Compressive Stress & Holding Time & Temperature \\
\hline 1 & $0.60 \mathrm{Rp} 0.2 / 459 \mathrm{MPa}$ & $500 \mathrm{~h}$ & $20^{\circ} \mathrm{C}$ \\
2 & $0.70 \mathrm{Rp} 0.2 / 535 \mathrm{MPa}$ & $500 \mathrm{~h}$ & $20{ }^{\circ} \mathrm{C}$ \\
3 & $0.80 \mathrm{Rp} 0.2 / 612 \mathrm{MPa}$ & $500 \mathrm{~h}$ & $20^{\circ} \mathrm{C}$ \\
4 & $0.80 \mathrm{Rp} 0.2 / 612 \mathrm{MPa}$ & $200 \mathrm{~h}$ & $20^{\circ} \mathrm{C}$ \\
5 & $0.85 \mathrm{Rp} 0.2 / 650 \mathrm{MPa}$ & $200 \mathrm{~h}$ & $20{ }^{\circ} \mathrm{C}$ \\
6 & $0.88 \mathrm{Rp} 0.2 / 670 \mathrm{MPa}$ & $200 \mathrm{~h}$ & $20^{\circ} \mathrm{C}$ \\
7 & $0.90 \mathrm{Rp} 0.2 / 688 \mathrm{MPa}$ & $500 \mathrm{~h}$ & $20^{\circ} \mathrm{C}$ \\
8 & $0.93 \mathrm{Rp} 0.2 / 711 \mathrm{MPa}$ & $500 \mathrm{~h}$ & $20^{\circ} \mathrm{C}$ \\
9 & $0.95 \mathrm{Rp} 0.2 / 726 \mathrm{MPa}$ & $500 \mathrm{~h}$ & $20^{\circ} \mathrm{C}$ \\
\hline
\end{tabular}




\section{Results and Discussion}

\subsection{Compressive Creep Behavior}

The nominal strain vs time curves of TA31 alloy under different compressive stress levels are shown in Figure 4, from which the variations of nominal strain with time can be directly obtained. The slope at any point of the curve represents the strain rate at the point. As can be seen from Figure 4, under the compression stresses of $0.60 \mathrm{Rp} 0.2,0.70 \mathrm{Rp} 0.2$, and $0.80 \mathrm{Rp} 0.2$, the nominal strain increases rapidly to $0.38 \%, 0.46 \%$, and $0.54 \%$ respectively in the initial stage of loading, and then the strain is experimental time independent, and no obvious creep strain is observed, which means there is no creep under the compression stresses of 0.60Rp0.2, 0.70Rp0.2, and 0.80Rp0.2.

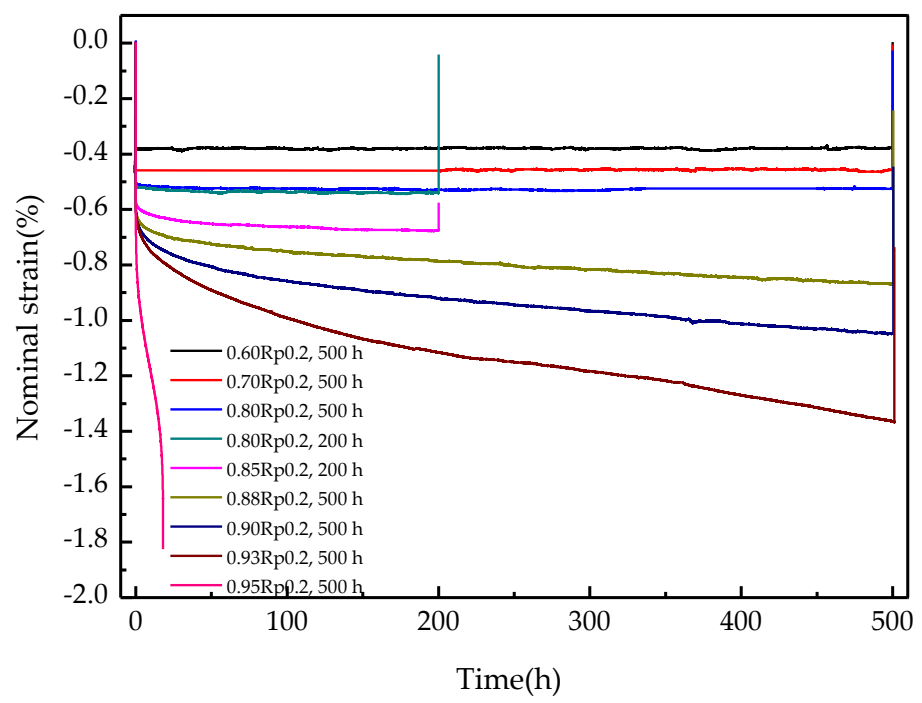

Figure 4. Strain-time curves of TA31 titanium alloy.

As the stress increasing and higher than a threshold stress, the creep strain apparently increases with creep time and significant creep appears. As shown in Figure 4, when the compressive stress is $0.85 R p 0.2,0.88 R p 0.2,0.90 R p 0.2$, and $0.93 R p 0.2$, the nominal strain increases gradually with the increase of holding time, which means there is a steady-state creep stage. The steady-state creep rate of TA31 alloy can be obtained by linear fitting of steady-state creep stage, as shown in Figure 5. The steady-state creep rates under compressive stresses of $0.85 \mathrm{Rp} 0.2,0.88 \mathrm{Rp} 0.2,0.90 \mathrm{Rp} 0.2$, and $0.93 \mathrm{Rp} 0.2$ are $4.20 \times 10^{-10} \mathrm{~s}^{-1}$, $9.01 \times 10^{-10} \mathrm{~s}^{-1}, 1.71 \times 10^{-9} \mathrm{~s}^{-1}$, and $3.74 \times 10^{-9} \mathrm{~s}^{-1}$ respectively.

Based on the above analysis, it can be concluded that there should be a threshold stress between 0.80Rp0.2 and 0.85Rp0.2. When the stress is higher than the threshold stress, several deformation mechanisms such as dislocation slip and twinning are possible to be activated, resulting in that the strain is time-dependent and increases gradually with the increase of holding time. The threshold stress can be thought as an important indication of whether or not the creep should be considered. A similar phenomenon has been reported at room temperature creep of titanium metals and alloys under tensile stress. Sato et al. [16] conducted tests on smooth bar specimens of CP-Ti and Ti-6Al-4V titanium alloys, and the work indicated that loads greater than $55 \%$ and $75 \%$ of the $0.2 \%$ offset yield strength (Rp0.2) are needed for the accumulation of significant creep strain for CP-Ti and Ti-6Al-4V titanium alloys respectively. Peng et al. [17] studied the creep of CP-Ti and found that there is a threshold stress in the low and intermediate temperature creep of CP-Ti. These existed literatures mainly focus on creep under tensile stress. By comparing with the published data, it can be concluded that the threshold stress for room temperature creep in the present study is higher than that in the published literature, which may be caused by the two different loading methods of compression and tension. Although the deformation mechanisms of tension and compression are both dislocation slip and twinning, there is 
anisotropy in tension and compression of titanium alloys [18,19]. Roberts et al. [20] found significant tension-compression asymmetry for $<\mathrm{c}+$ a $>$ pyramidal slip in Ti-6Al alloy, and the critical resolved shear stress increase to $820 \mathrm{MPa}$ under compression and decrease to $558 \mathrm{MPa}$ in tension. Jones et al. [21] found that uniaxial compression along the c-axis the $<c+a>$ dislocations cross-slip readily, but they do not do so in uniaxial tension, and a tensile normal stress decreased the critical resolves shear stress compared to a compressive normal stress. Studies on single colony crystals of Ti-6242Si showed significant tension/compression asymmetry in the critical resolved shear stress for <a>-type basal slip. Slip line studies of colony crystals showed very coarse, planar slip in compression, but very homogeneous, wavy slip in tension, which indicate an easier cross slip in tension [22].
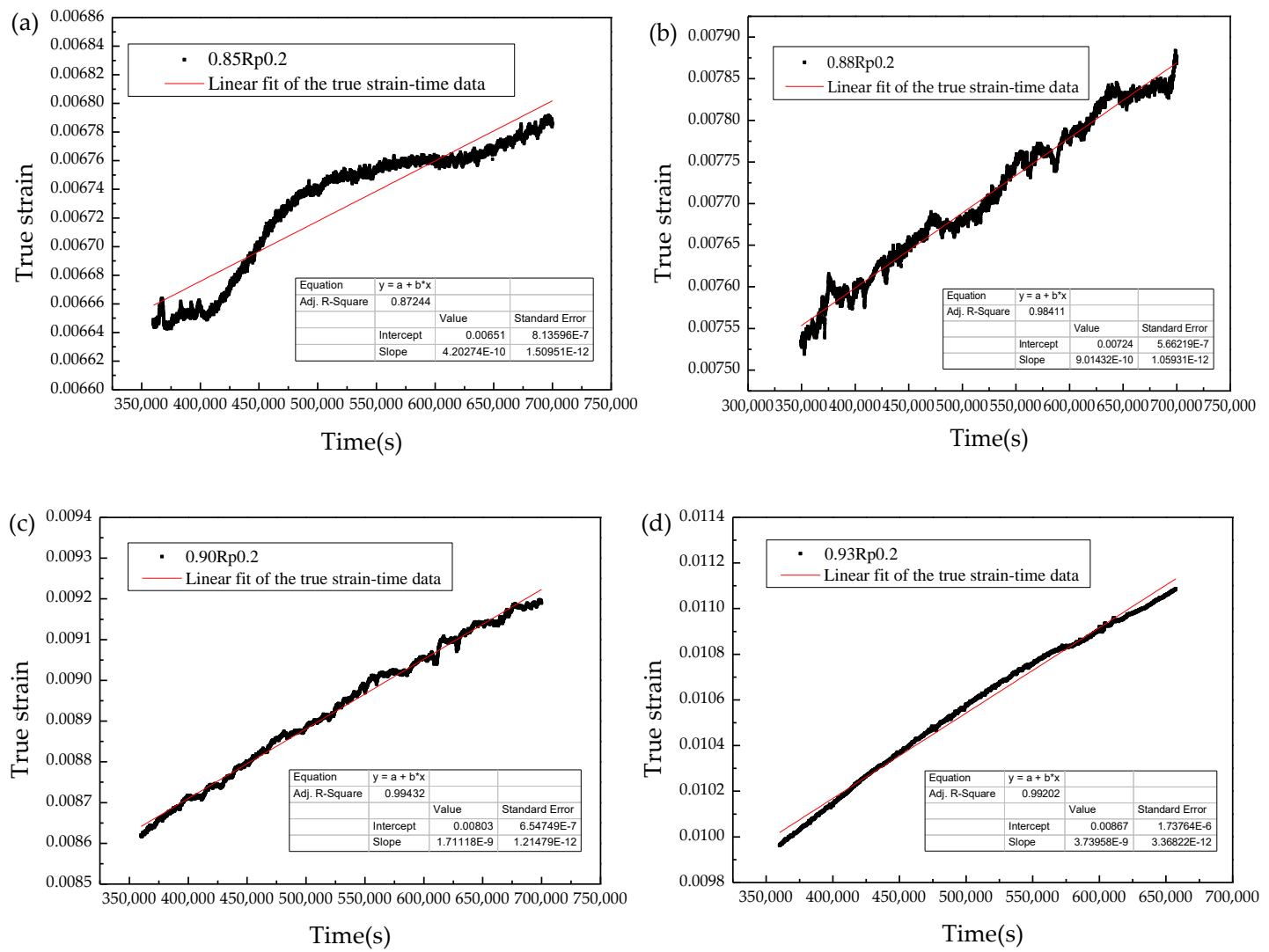

Figure 5. Linear fit of the true strain-time curve of TA31 alloy in the steady creep stage under compressive stresses of (a) 0.85Rp0.2; (b) 0.88Rp0.2; (c) 0.90Rp0.2; (d) 0.93Rp0.2.

When the compressive stress reaches $0.95 \mathrm{Rp} 0.2$, the sample loses its stability rapidly. It can be concluded that there should be another threshold stress between 0.93Rp0.2 and 0.95Rp0.2. When the compressive stress reaches threshold stress, the sample enters the accelerating creep stage directly.

Lastly, the extensometer was monitored during the load removal in order to evaluate whether the deformation was elastic or plastic in nature. The strain-stress curves of TA31 alloy under uniaxial compression stress are shown in Figure 6, from which the variation of strain with stress during the loading, stress maintaining, and unloading processes are directly obtained. As can be seen from Figure 6, the strain increases linearly with the increasing of stress in the loading stage. During the stress maintaining stage, the strain gradually increases to the maximum value, and the maximum nominal strain depends on the stress and the stress maintaining time. In the unloading stage, the nominal strain decreases linearly with the decrease of stress, which is caused by the elimination of elastic strain. The strain after the stress is completely removed is called residual strain. 


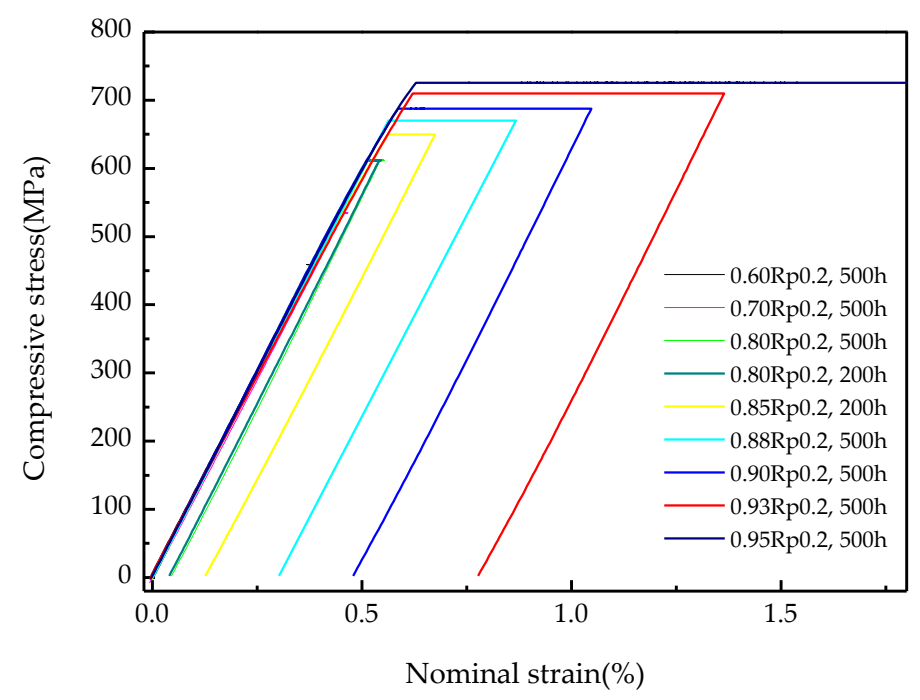

Figure 6. Stress-strain curves of TA31 titanium alloy.

The maximum strain and residual strain in the compression process of TA31 alloy are shown in Table 3. As can be seen from Table 3, the maximum strain and the residual strain are $0.543 \%$ and $0.040 \%$ respectively under the compressive stress of $0.80 \mathrm{Rp} 0.2$ to the holding time of $200 \mathrm{~h}$, whereas the two values are $0.543 \%$ and $0.045 \%$ respectively under the same compressive stress of $0.80 \mathrm{Rp} 0.2$ to the holding time of $500 \mathrm{~h}$, from which it is demonstrated that when the compressive stress is $0.80 \mathrm{Rp} 0.2 \mathrm{or}$ lower there is no creep.

Table 3. Maximum strain and residual strain in compression of TA31 alloy.

\begin{tabular}{cccccc}
\hline Test No. & $\begin{array}{c}\text { Compressive } \\
\text { Stress }\end{array}$ & $\begin{array}{c}\text { Holding Time } \\
\text { (h) }\end{array}$ & $\begin{array}{c}\text { Maximum } \\
\text { Strain (\%) }\end{array}$ & $\begin{array}{c}\text { Residual } \\
\text { Strain (\%) }\end{array}$ & Remarks \\
\hline 1 & $0.60 R p 0.2$ & 500 & 0.381 & 0.001 & - \\
2 & $0.70 R p 0.2$ & 500 & 0.463 & 0.004 & - \\
3 & $0.80 R p 0.2$ & 500 & 0.543 & 0.045 & - \\
4 & $0.80 R p 0.2$ & 200 & 0.543 & 0.040 & - \\
5 & $0.85 R p 0.2$ & 200 & 0.674 & 0.126 & - \\
6 & $0.88 R p 0.2$ & 500 & 0.868 & 0.303 & - \\
7 & $0.90 R p 0.2$ & 500 & 1.048 & 0.479 & - \\
8 & $0.93 R p 0.2$ & 500 & 1.364 & 0.777 & Loses stability \\
9 & $0.95 R p 0.2$ & 500 & - & - & \\
\hline
\end{tabular}

\subsection{Compression Creep Model}

In the creep test of metals and alloys, the most important parameter is the steady-state creep rate $[23,24]$. The dependence of compressive creep stress on the temperature and strain rate is generally expressed in terms of three kinetic equations given by

$$
\begin{gathered}
\dot{\varepsilon} \exp \left(\frac{Q}{R T}\right)=A(\sigma)^{n} \\
\dot{\varepsilon} \exp \left(\frac{Q}{R T}\right)=A_{1} \exp \left(n_{1} \sigma\right) \\
\dot{\varepsilon} \exp \left(\frac{Q}{R T}\right)=A_{2} \sinh (\alpha \sigma)^{n_{2}}
\end{gathered}
$$

where $A, A_{1}, A_{2}$, and $\alpha$ are constants; $\dot{\varepsilon}$ is the strain rate $\left(\mathrm{s}^{-1}\right), \sigma$ is the stress $(\mathrm{MPa}) ; Q$ is the activation energy of deformation $(\mathrm{kJ} / \mathrm{mol}) ; R$ is the gas constant $\left(8.3145 \mathrm{~J} \cdot \mathrm{mol}^{-1} \cdot \mathrm{K}^{-1}\right) ; T$ is the absolute deformation temperature $(\mathrm{K}) ; n, n_{1}$, and $n_{2}$ are the stress exponents [25-28]. 
Equations (1)-(3) can be written as Equations (4)-(6) respectively by taking a logarithm transformation of both side of the formulas

$$
\begin{gathered}
\ln \sigma=\ln \dot{\varepsilon} / n+Q /(n R T)-\ln A / n \\
\sigma=\ln \dot{\varepsilon} / n 1+Q /(n 1 R T)-\ln A 1 / n 1 \\
\ln [\sinh (\alpha \sigma)]=\ln \dot{\varepsilon} / n_{2}+Q /\left(n_{2} R T\right)-\ln A_{2} / n_{2}
\end{gathered}
$$

Based on the experimental data, the curve of $\ln (\sigma)$ vs. $\ln \dot{\varepsilon}$ can be plotted, as shown in Figure 7, from which it can be concluded that Equation (4) is suitable for the creep model of the TA31 titanium alloy.

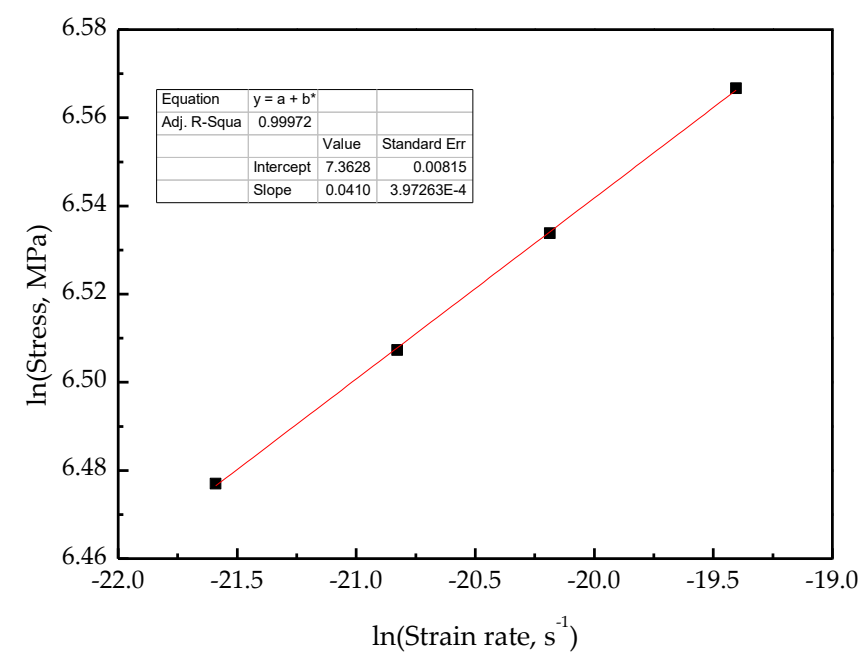

Figure 7. Variation of the creep stress with strain rate.

When the creep deformation temperature is $20^{\circ} \mathrm{C}, \ln A-Q /(R T)=K$ is a constant and Equation (4) can be expressed as

$$
\ln \sigma=\ln \dot{\varepsilon} / n+Q /(n R T)-\ln A / n
$$

The values of $n$ and $K$ can be derived from the slope and intercept of the linear fitting line of $\ln (\sigma)$ vs. $\ln \dot{\varepsilon}$ as shown in Figure 7. The values of $n$ and $K$ in the present study are -179.71 and 24.41 , respectively.

Therefore, the creep model of TA31 titanium alloy can be expressed as Equation (8)

$$
\ln \dot{\varepsilon}=-179.71+24.41 \ln \sigma,
$$

which can be written as Equation (9)

$$
\dot{\varepsilon}=e^{-179.71} \sigma^{24.41}
$$

On account of the creep model, the creep rate of TA31 titanium alloy in the steady-state creep stage under different compressive stress levels can be calculated. Figure 8 and Table 4 illustrate a comparison of the calculated with the experimental strain rate of TA31 titanium alloy. The mean difference between the calculated with the experimental strain rate of TA31 titanium alloy is $2.54 \%$, suggesting the effectiveness and reliability of the creep model in predicting the creep behavior of TA31 alloy. 


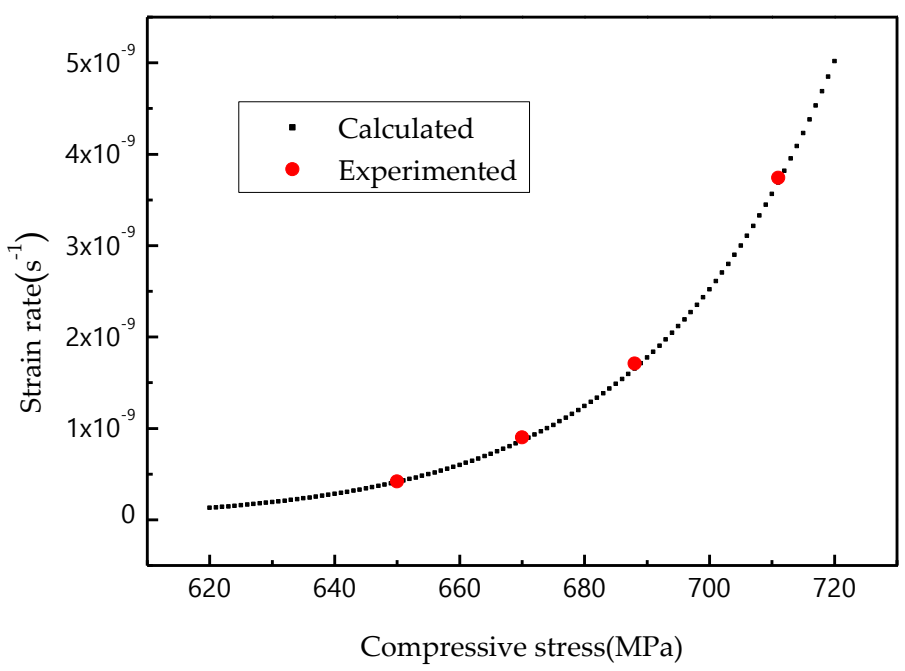

Figure 8. Comparison of calculated with experimental creep strain rate of TA31 titanium alloy.

Table 4. Comparison of calculated with experimental creep strain rate of TA31 titanium alloy.

\begin{tabular}{ccccc}
\hline \multirow{2}{*}{$\begin{array}{c}\text { Compressive } \\
\text { Stress (MPa) }\end{array}$} & \multicolumn{2}{c}{ Strain Rate $\mathbf{s}^{\mathbf{- 1}}$ ) } & \multirow{2}{*}{ Error } & \multirow{2}{*}{ Remarks } \\
\cline { 2 - 3 } & Experimented & Calculated & & $1.62 \%$ \\
650 & $4.20 \times 10^{-10}$ & $4.13 \times 10^{-10}$ & \\
670 & $9.01 \times 10^{-10}$ & $8.66 \times 10^{-10}$ & $3.91 \%$ & $\Delta$ \\
688 & $1.71 \times 10^{-9}$ & $1.65 \times 10^{-9}$ & $3.29 \%$ & \\
711 & $3.74 \times 10^{-9}$ & $3.69 \times 10^{-9}$ & $1.33 \%$ & \\
\hline
\end{tabular}

is - The experimental data had been used in the establishment process of the model; $\triangle$-The experimental data had not been used in the establishment process of the model.

\section{Conclusions}

In this work, the creep behavior of a near $\alpha$ TA31 titanium alloy under different compressive pressures has been investigated at room temperature. The creep model of TA31 alloy has been built by using the regression method. The effectiveness and reliability of this model has been verified. The following main results are obtained.

(1) There is a steady-state creep stage in the TA31 titanium alloy at the compressive stresses between $0.85 \mathrm{Rp} 0.2$ and $0.93 \mathrm{Rp} 0.2$, in which the strain rate is approximately a constant value. When the compressive stress is $0.80 \mathrm{Rp} 0.2$ or lower, there is no creep. When the compressive stress reaches a threshold stress between $0.93 \mathrm{Rp} 0.2$ and $0.95 \mathrm{Rp} 0.2$, the sample enters the accelerated creep stage directly.

(2) The creep model of TA31 titanium alloy has been established, from which the creep strain rate of TA31 titanium alloy in the steady-state creep stage under different compressive stresses can be calculated, and the mean difference between the calculated and the experimental value is $2.54 \%$.

Author Contributions: Conceptualization, W.Y. and J.Z.; methodology, S.H.; validation, W.Y.; formal analysis, Z.Y.; investigation, J.Z.; resources, S.H. and Z.Y.; data curation, S.L.; writing-original draft preparation, W.Y.; writing-review and editing, S.L. All authors have read and agreed to the published version of the manuscript.

Funding: The research was funded by the Key Scientific Research Projects of Colleges and Universities in Henan Province (grant no. 19B430008), National Natural Science Foundation of China (grant no. 51801171), and Fundamental Research Funds for the Central Universities (2018GF13).

Conflicts of Interest: The authors declare no conflict of interest. 


\section{References}

1. Banerjee, D.; Williams, J.C. Perspectives on Titanium Science and Technology. Acta Mater. 2013, 61, 844-879. [CrossRef]

2. Liu, Y.; Chen, F.; Xu, G.; Cui, Y.; Chang, H. Correlation between microstructure and mechanical properties of heat-treated Ti-6Al-4V with Fe alloying. Metals 2020, 10, 854. [CrossRef]

3. Zhang, J.; Zhang, M.; Cui, W.C.; Tang, W.X.; Wang, F.; Pan, B.B. Elastic-plastic buckling of deep sea spherical pressure hulls. Mar. Struct. 2018, 57, 38-51. [CrossRef]

4. Sagalevich, A.M. 30 years experiences of Mir submersibles for the ocean operations. Deep Sea Res. Part II Top. Stud. Oceanogr. 2018, 155, 83-95. [CrossRef]

5. Tanaka, H.; Yamada, T.; Sato, E.; Jimbo, I. Distinguishing the ambient temperature creep region in a deformation mechanism map of annealed CP-Ti. Scripta Mater. 2006, 54, 121-124. [CrossRef]

6. Ankem, S.; Wyatt, Z.W.; Joost, W. Advances in low-temperature $(<0.25 \mathrm{Tm})$ creep behavior of single and two-phase titanium alloys. Procedia Eng. 2013, 55, 10-16. [CrossRef]

7. Oberson, P.G.; Ankem, S. The effect of time-dependent twinning on low temperature $(<0.25 \mathrm{Tm}) \mathrm{creep}$ of an alpha-titanium alloy. Int. J. Plast. 2009, 25, 881-890. [CrossRef]

8. Gollapudi, S.; Charit, I.; Murty, K.L. Creep mechanisms in Ti-3Al-2.5V alloy tubing deformed under closed-end internal gas pressurization. Acta Mater. 2008, 56, 2406-2419. [CrossRef]

9. Wang, T.B.; Li, B.L.; Wang, Z.Q.; Nie, Z.R. A microstructure with improved thermal stability and creep resistance in a novel near-alpha titanium alloy. Mater. Sci. Eng. A 2018, 731, 12-20. [CrossRef]

10. He, Y.S.; Hu, R.; Luo, W.Z.; He, T.; Lai, Y.J.; Du, Y.J.; Liu, X.H. Microstructural evolution and creep deformation behavior of novel Ti-22Al-25Nb-1Mo-1V-1Zr-0.2Si (at.\%) orthorhombic alloy. Trans. Nonferr. Met. Soc. China 2019, 29, 313-321. [CrossRef]

11. Viespoli, L.M.; Bressan, S.; Itoh, T.; Hiyoshi, N.; Prashanth, K.G.; Berto, F. Creep and high temperature fatigue performance of as build selective laser melted Ti-based $6 \mathrm{Al}-4 \mathrm{~V}$ titanium alloy. Eng. Fail. Anal. 2020, 111, 104477. [CrossRef]

12. Nie, X.; Liu, H.Q.; Zhou, X.Z.; Yi, D.Q.; Huang, B.Y.; Hu, Z.; Xu, Y.F.; Yang, Q.; Wang, D.C.; Gao, Q. Creep of Ti-5Al-5Mo-5V-1Fe-1Cr alloy with equiaxed and lamellar microstructures. Mater. Sci. Eng. A 2016, 651,37-44. [CrossRef]

13. Gu, Y.; Zeng, F.H.; Qi, Y.L.; Xia, C.Q.; Xiong, X. Tensile creep behavior of heat-treated TC11 titanium alloy at 450-550 ${ }^{\circ}$ C. Mater. Sci. Eng. A 2013, 575, 74-85. [CrossRef]

14. Doraiswamy, D.; Ankem, S. The effect of grain size and stability on ambient temperature tensile and creep deformation in metastable beta titanium alloys. Acta Mater. 2003, 51, 1607-1619. [CrossRef]

15. Briguente, L.A.N.S.; Oñoro, J.; Briguente, F.P.; Resende, F.A.; Reis, J.L.; Reis, D.A.P.; Oliveira, A.C. The influence of laser nitriding on creep behavior of Ti-4Al-4V alloy with widmanstätten microstructure. Metals 2019, 9, 236. [CrossRef]

16. Sato, E.; Yamada, T.; Tanaka, H.; Jimbo, I. Categorization of ambient-temperature creep behavior of metals. Mater. Trans. 2006, 47, 1121-1126. [CrossRef]

17. Peng, J.; Zhou, C.Y.; Dai, Q.; He, X.H. The temperature and stress dependent primary creep of CP-Ti at low and intermediate temperature. Mater. Sci. Eng. A 2014, 611, 123-135. [CrossRef]

18. Tuninetti, V.; Gilles, G.; Milis, O.; Pardoen, T.; Habraken, A.M. Anisotropy and tension-compression asymmetry modeling of the room temperature plastic response of Ti-6Al-4V. Int. J. Plast. 2015, 67, 53-68. [CrossRef]

19. Lin, P.; Hao, Y.; Zhang, B.; Zhang, S.; Chi, C.; Shen, J. Tension-compression asymmetry in yielding and strain hardening behavior of CP-Ti at room temperature. Mater. Sci. Eng. A 2017, 707, 172-180. [CrossRef]

20. Roberts, W.; Gong, J.; Wilkinson, A.J.; Tarleton, E. Tension-compression asymmetry of <c+a $>$ slip in Ti-6Al. Scr. Mater. 2020, 178, 119-123. [CrossRef]

21. Jones, I.P.; Hutchinson, W.B. Stress-state dependence of slip in Titanium-6Al-4V and other H.C.P. metals. Acta Metall. 1981, 29, 951-968. [CrossRef]

22. Neeraj, T.; Savage, M.F.; Tatalovich, J.; Kovarik, L.; Hayes, R.W.; Mills, M.J. Observation of tensioncompression asymmetry in a and a/b titanium alloys. Philos. Mag. 2005, 85, 279-295. [CrossRef]

23. Ma, X.K.; Li, F.G.; Zhao, C.; Zhu, G.; Li, W.N.; Sun, Z.K.; Yuan, Z.W. Indenter load effects on creep deformation behavior for Ti-10V-2Fe-3Al alloy at room temperature. J. Alloy Comp. 2017, 709, 322-328. [CrossRef] 
24. Zhang, W.D.; Liu, Y.; Wu, H.; Lan, X.D.; Qiu, J.W.; Hu, T.; Tang, H.P. Room temperature creep behavior of Ti-Nb-Ta-Zr-O alloy. Mater. Charact. 2016, 118, 29-36. [CrossRef]

25. Li, M.Q.; Pan, H.S.; Lin, Y.Y.; Luo, J. High temperature deformation behavior of near alpha Ti-5.6Al-4.8Sn-2.0Zr alloy. J. Mater. Process. Tech. 2007, 183, 71-76. [CrossRef]

26. Ma, D.W.; Li, M.Q.; Luo, J.; Yu, W.X.; Su, S.B.; Wu, J.L. Flow stress model considering contribution of strain in isothermal compression of 7A09 aluminum alloy. Chin. J. Nonferr. Met. 2011, 21, 954-960.

27. Singh, V.; Mondal, C.; Sarkar, R.; Bhattacharjee, P.P.; Ghosal, P. Compressive creep behavior of a $\gamma$-TiAl based Ti-45Al-8Nb-2Cr-0.2B alloy: The role of $\beta(\mathrm{B} 2)$-phase and concurrent phase transformations. Mater. Sci. Eng. A 2020, 774, 138891. [CrossRef]

28. Wu, F.; Xu, W.; Jin, X.; Zhong, X.; Wan, X.; Shan, D.; Guo, B. Study on hot deformation behavior and microstructure evolution of Ti-55 high-temperature titanium alloy. Metals 2017, 7, 319.

C 2020 by the authors. Licensee MDPI, Basel, Switzerland. This article is an open access article distributed under the terms and conditions of the Creative Commons Attribution (CC BY) license (http://creativecommons.org/licenses/by/4.0/). 